\title{
Characteristics of bulk liquid undercooling and crystallization behaviors of jet electrodeposition Ni-W-P alloy
}

\author{
J K YU*, Y H WANG, G Z XING, Q QIAO, B LIU, Z J CHU, C L LI and F YOU \\ State Key Laboratory of Metastable Materials Science and Technology, Yanshan University, \\ Qinhuangdao 066004, Hebei, PR China
}

MS received 16 March 2014; revised 28 May 2014

\begin{abstract}
The undercooling of Ni-W- P ternary alloy coating melt was investigated by in situ differential scanning calorimeter (DSC) with the flux processing technique. The results showed that the highest undercooling of Ni-W-P ternary alloy with $359 \mathrm{~K}$ was obtained as the thermal treatment temperature of the melt being $1679 \mathrm{~K}$ and the cooling rate being $50 \mathrm{~K} \mathrm{~min}^{-1}$. When cooling rate is fixed, the change of undercooling depends on the melt processing temperature, and the undercooling will increase rapidly at the first stage. The effects of thermal treatment temperature and cooling rates on the undercooling were discussed.
\end{abstract}

Keywords. Characterization; undercooling solidification; differential scanning calorimeter (DSC); flux processing technique; jet electrodeposition; Ni-W-P ternary alloy.

\section{Introduction}

Ni-P binary alloys have been widely studied in scientific community owing to their characterization of good corrosion resistance, high hardness, wear resistance and a series of advantages. ${ }^{1-4}$ In order to meet the engineering application as coating, some metals like tungsten and tin are added in $\mathrm{Ni}-\mathrm{P}$ matrix to further enhance their properties. ${ }^{5,6}$ Among them, Ni-W-P ternary alloy has received considerable attention because tungsten possesses unique properties such as high melting point $\left(3410^{\circ} \mathrm{C}\right)$, low coefficient of linear thermal expansion and high tensile strength. Therefore, it is expectant to obtain Ni-W-P ternary alloy with excellent mechanical properties like hardness and strength, physical properties like thermal stability and electricity and so on. Much work has been carried out on its corrosion behavior, wear behavior, microstructure, phase transformation, thermal stability, composition, microhardness and preparation of $\mathrm{Ni}-\mathrm{W}-\mathrm{P}$ alloys. ${ }^{7-19}$ However, study on the degree of undercooling of Ni-W-P ternary alloys has not been concerned more, despite that undercooling is a native characteristic for alloy during solidification and a deep knowledge of undercooling of Ni-W-P alloy will help to control the metastable formation, grain refinement and composition homogenization to optimize the properties of $\mathrm{Ni}-\mathrm{W}-\mathrm{P}$ ternary alloy for engineering application.

Knowledge of undercooling of alloy, especially for deep undercooling of melts, is useful as deep undercooling of melts is an important method for realizing non-equilibrium solidification and obtaining metastable phase. ${ }^{20,21}$ In fact, many melts are in undercooled state before crystallization.

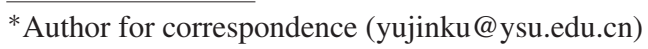

However, owing to the low cooling rates and the heterogeneous nucleation caused by container walls and impurities in melt, the undercooling of melts is not high enough. It is well known that there are two methods in realizing deep undercooling. One is by rapid cooling, so that the crystallization process is postponed or the melt is frozen due to the kinetics reason. The disadvantage may be that the solidification process is too rapid to observe their microstructure evolution, to obtain the information for the nucleation and crystal growth and to determine the thermal-physical properties of the melts directly. Another is by using containerless methods of flux processing and levitation processing technology, etc. to restrain the heterogeneous nucleation, and therefore to obtain deep undercooling for melts. ${ }^{22-24}$ The advantage of the latter is that a deep undercooling can be easily realized even in low cooling rates and the melt of deep undercooling can be kept in liquid for a longer time without solidification. Some containerless processing techniques like electrostatic levitation, electromagnetic levitation have been used to investigate the deep undercooling of melt and the non-equilibrium solidification of metals, alloys and oxides. ${ }^{25-27}$ However, the knowledge about the solidification and the thermal-physical properties of melts in deep undercooling melt is still unclear. Therefore, it is possible to investigate the microstructure evolution, the law of the nucleation and crystal growth and the determination of the thermalphysical properties. ${ }^{28,29}$ Some containerless processing techniques like electrostatic levitation, electromagnetic levitation have been used to investigate the deep undercooling of melt and the non-equilibrium solidification of metals. ${ }^{25-27}$

Considering the studies of undercooling of Ni-W-P ternary alloy melts are of great importance, the aim of present work is to investigate the deep undercooling and crystallization 
of Ni-W-P ternary alloy precisely by differential scanning calorimeter (DSC) with flux processing technology. The obtained foundation data will be useful for future materials science research and will help to control the metastable phase $\mathrm{Ni}_{5} \mathrm{P}_{2}$ and $\mathrm{Ni}_{12} \mathrm{P}_{5}$, etc. formation, grain refinement and composition homogenization to optimize the properties of $\mathrm{Ni}-\mathrm{W}-\mathrm{P}$ ternary alloy for engineering application.

\section{Experimental}

Ni-20 wt $\%$ W-12 wt\% P alloy coatings were prepared by high-speed jet electrodeposition (JED) technology. The substrates for the plating were pure copper (or stainless steel) with a size of $\varphi 18 \mathrm{~mm} \times 2 \mathrm{~mm}$. They were firstly ground with emery paper of 400, 800, 1200 grit, degreased in acetone, cathodically cleaned in bath $\left(\mathrm{NaOH} 60 \mathrm{~g}^{-1}, \mathrm{Na}_{2} \mathrm{CO}_{3}\right.$ $15 \mathrm{~g} \mathrm{l}^{-1}, \mathrm{Na}_{3} \mathrm{PO}_{4} 15 \mathrm{~g} \mathrm{l}^{-1}, \mathrm{Na}_{2} \mathrm{SiO}_{3} 5 \mathrm{~g} \mathrm{l}^{-1}$ at $25^{\circ} \mathrm{C}$ ), and rinsed in running water and deionized water. Thus, degreased sample was deoxidized in activated for $10 \mathrm{~s}$ in a bath containing $10 \%$ in weight $\mathrm{H}_{2} \mathrm{SO}_{4}$ and $100 \mathrm{ml} \mathrm{l}^{-1} \mathrm{H}_{2} \mathrm{O}_{2}(35 \%)$ at room temperature, rinsed in running water and deionized water. Finally, the sample was put into the jet electrodeposition mould for jet electrodeposition. Ni-W-P alloy coatings were prepared by altering the chemistry solution with proper ratio of Ni:W:P solution. That is, $\mathrm{pH}$ value of the bath used in the jet electrodeposition plating was adjusted to 5.5-6.5 by $10 \%$ sulfuric acid, and the reaction temperature of the coatings keeps $50-55^{\circ} \mathrm{C}$. The compositions of the bath and the deposition conditions for Ni-W-P alloy coatings are shown in table 1. The selection of using JED technology instead of electroless deposition technology was that it was easy to obtain thick coating material for further sample preparation. The composition of the Ni-W-P alloy coating was determined by fluorescence analysis and chemical analysis.

Dehydrated $\mathrm{K}_{2} \mathrm{SO}_{4}$ was used as flux. Flux processing is a quasi-containerless technology to realize deep undercooling in melts. Using this technology, the melt samples were embedded in the liquid flux to avoid contacting with the container walls of the crucible and they were applied successively heating-cooling cycles. Thus, the melt samples would

Table 1. Composition and operating conditions of the plating baths.

\begin{tabular}{ll}
\hline Constituents of plating bath & Concentration $\left(\mathrm{g} \mathrm{l}^{-1}\right)$ \\
\hline $\mathrm{NiSO}_{4} \cdot 6 \mathrm{H}_{2} \mathrm{O}$ & $200-250$ \\
$\mathrm{Na}_{2} \mathrm{WO}_{4} \cdot 2 \mathrm{H}_{2} \mathrm{O}$ & $60-65$ \\
$\mathrm{NaH}_{2} \mathrm{PO}_{2} \cdot \mathrm{H}_{2} \mathrm{O}$ & $10-20$ \\
$\mathrm{C}_{6} \mathrm{H}_{5} \mathrm{Na}_{3} \mathrm{O}_{7} \cdot 2 \mathrm{H}_{2} \mathrm{O}$ & $80-100$ \\
$\mathrm{H}_{3} \mathrm{BO}_{3}$ & $35-40$ \\
Operating conditions & \\
Temperature $\left({ }^{\circ} \mathrm{C}\right)$ & $50-55$ \\
pH & $5.5-6.5$ \\
Jet velocity $\left(\mathrm{m} \mathrm{s}^{-1}\right)$ & $2-8.5$ \\
\hline
\end{tabular}

be purged and the influence of the induced heterogeneous particles would be diminished.

Undercooling was measured by DSC (STA449C/6/G) with $\alpha-\mathrm{Al}_{2} \mathrm{O}_{3}$ crucibles. The chamber containing the crucible was first evacuated to $10^{-2} \mathrm{~Pa}$, and then filled with high pure argon gas that flew recycling six times to guarantee a protected atmosphere during the experiments. The $\alpha-\mathrm{Al}_{2} \mathrm{O}_{3}$ crucible was used to obtain baseline and experimental curves. The weight of the Ni-W-P alloy samples ranges in $2.0-4.0 \mathrm{mg}$ while the dehydrated $\mathrm{K}_{2} \mathrm{SO}_{4}$ keeps nearly constant of around $10 \mathrm{mg}$ for all the measurements. The cooling rates selected in the experiments varied from $10,20,30,40$ to $50 \mathrm{~K} \mathrm{~min}^{-1}$. Every sample was hold for $30 \mathrm{~min}$ at $313.15 \mathrm{~K}$, in other word, $40^{\circ} \mathrm{C}$, to assure the repeatability of the experiments. Before the experiments, temperature and energy were calibrated by standard materials like In, Sn, Zn, Al, Ag, Au and $\mathrm{Ni}$ in the mode of heating and cooling rate from 10, 20, 30,40 to $50 \mathrm{~K} \mathrm{~min}^{-1}$, respectively.

\section{Results and discussion}

\subsection{Undercooling}

Figure 1 shows the DSC curves of the Ni-W-P ternary alloy The cooling rates selected in the experiments varied from 10 , $20,30,40$ to $50 \mathrm{~K} \mathrm{~min}^{-1}$. It can be seen in figure 1 that during the heating run, an endothermic signal was observed at $1359 \mathrm{~K}$, corresponding to the occurrence of melting. Upon cooling the melt, an exothermic peak was detected at $1000 \mathrm{~K}$, which corresponds to the crystallization starting temperature. The obtained undercooling $(\Delta T)$ for Ni-W-P ternary alloy can thus be calculated as $359 \mathrm{~K}$ in this case. This result was higher than Ni-P binary alloy with $310 \mathrm{~K}^{1}$

Figure 2 shows the correlation between the undercooling $(\Delta T)$ and the cooling rate $(\varphi)$ of the Ni-W-P alloy

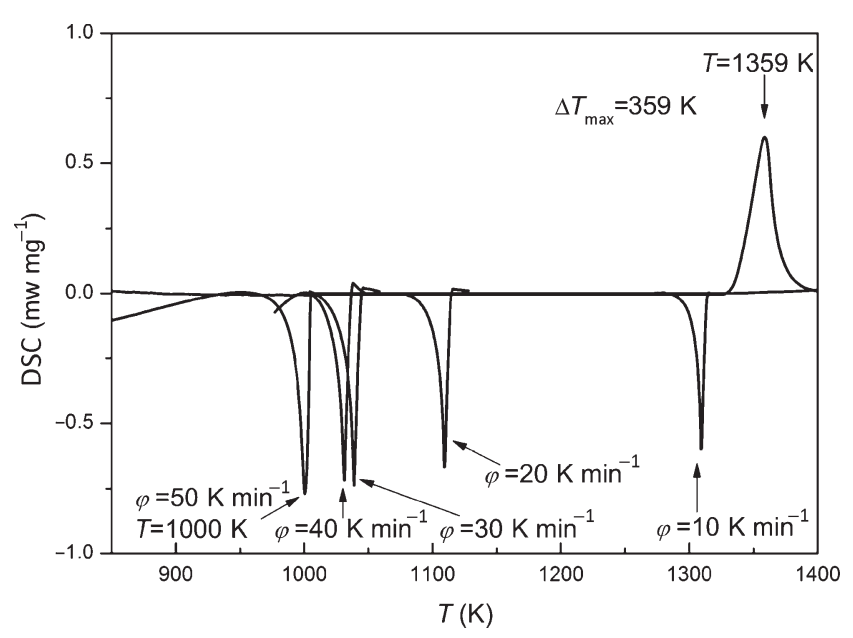

Figure 1. DSC curves of the Ni-W-P ternary alloy. The same degree of superheat, cooling speed faster fully crystallized temperature is low. 
coating melt obtained by the DSC results in this work. The samples were heated to $1559 \mathrm{~K}$, that is, $200 \mathrm{~K}$ over the melting temperature of the alloy. It can be seen in figure 2 that the undercooling of the alloy increases rapidly from 50 to $358 \mathrm{~K}$ with an increase of cooling rate from 10 to $40 \mathrm{~K} \mathrm{~min} \mathrm{~m}^{-1}$. As the cooling rate increases from 40 to $50 \mathrm{~K} \mathrm{~min}^{-1}$, the undercooling increases slightly from 358 to $359 \mathrm{~K}$. This experimental result has been confirmed by theoretic analysis that the undercooling enhances with the increase of cooling rate. ${ }^{30}$

The relationship between the maximum undercooling $(\Delta T)$ and the treated temperature $(\theta)$ of the Ni-W-P ternary alloy was shown in figure 3 . An increase of the temperatures would remelt and passivate the inclusion in the melt, and

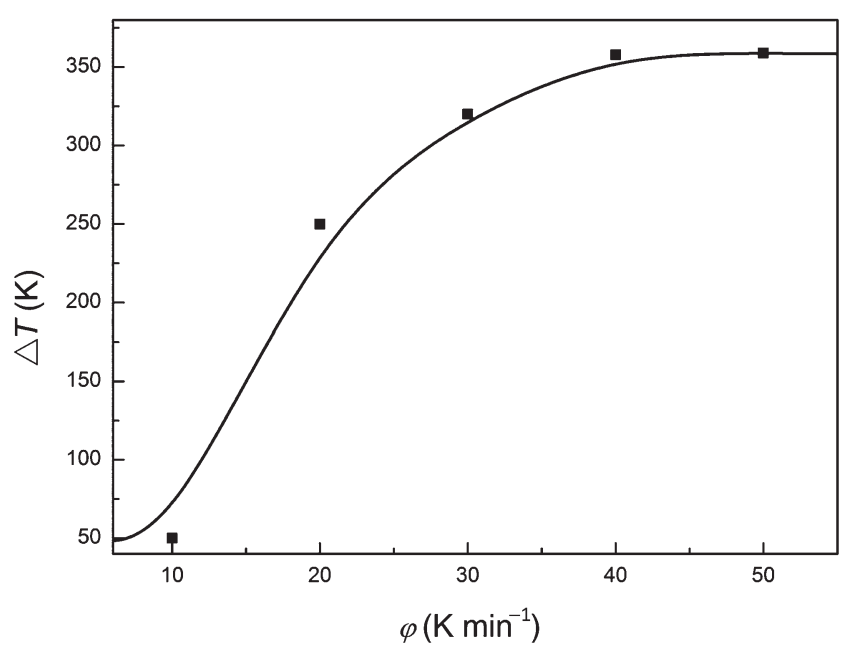

Figure 2. Relation between the undercooling $(\Delta T)$ and the cooling rate $(\varphi)$ of the Ni-W-P ternary alloy. The same degree of superheat, the undercooling enhances with the increase of cooling rate.

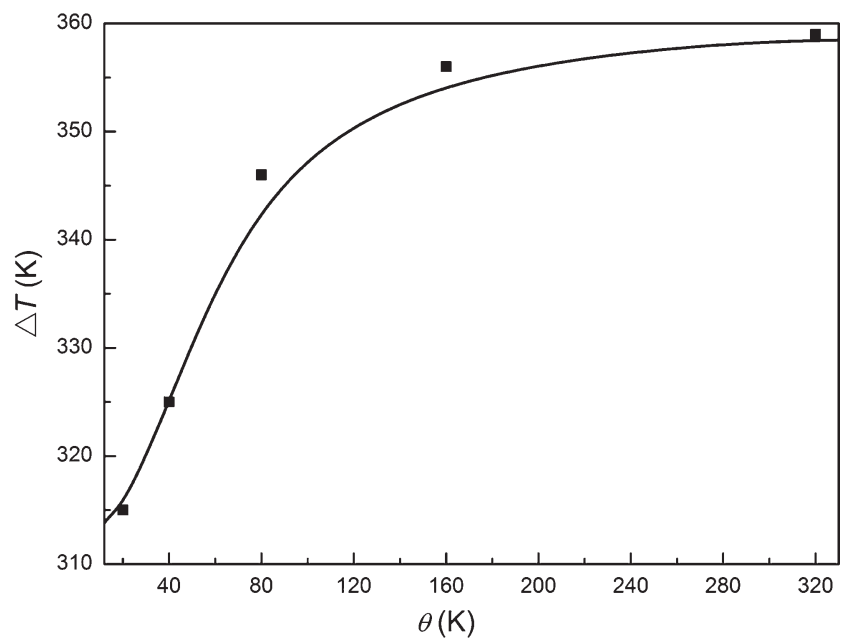

Figure 3. Relation between the maximum undercooling $(\Delta T)$ and the treated temperature $(\theta)$ of the Ni-W-P ternary alloy. The same cooling rate, the undercooling enhances with the increase of superheat. thus would reduce the heterogeneous nucleation. Even more, it would decrease the possibility of the heredity of atom cluster, which was helpful to obtain high undercooling. The Ni-W-P ternary alloy coating melt was first heated over its melting temperature $\left(T_{\mathrm{m}}=1359 \mathrm{~K}\right)$ for $20,40,80,160$ and $320 \mathrm{~K}$, respectively, and then was cooled at a cooling rate of $40 \mathrm{~K} \mathrm{~min}^{-1}$. The undercooling of the alloy varied sharply, from 314 to $358 \mathrm{~K}$, with the increase of the experimental temperature from 10 to $160 \mathrm{~K}$ over the melting temperature, respectively. An increase of the experimental temperature from 160 to $320 \mathrm{~K}$ will lead to an increase of the undercooling slightly, from 356 to $359 \mathrm{~K}$. When the temperature was over the $T_{\mathrm{m}}$ of the Ni-W-P ternary alloy for $160 \mathrm{~K}$, the undercooling varied slightly. As increasing the experimental temperature from 1359 to $1519 \mathrm{~K}$, about $160 \mathrm{~K}$ over the $T_{\mathrm{m}}$ of the Ni-W-P ternary alloy coating, a deep undercooling of the melt would be obtained by increasing the overheating. The result indicated that a deep undercooling would be obtained by increasing the overheating temperature at a given cooling rate. Otherwise, the effect of overheating on the undercooling of Ni-W-P alloy coating was very small.

\subsection{Non-isothermal crystallization kinetics}

Non-isothermal crystallization kinetics of Ni-W-P ternary alloy coating can be analyzed by the curves of coolsolidification. Before analyzing the data, the relative crystallization needs to be calculated. The relative crystallization is the function of temperature, and can be expressed as:

$$
X_{\mathrm{t}}=\int_{T_{0}}^{T}\left(\mathrm{~d} H_{\mathrm{c}} / \mathrm{d} T\right) \mathrm{d} T / \int_{T_{0}}^{T_{\infty}}\left(\mathrm{d} H_{\mathrm{c}} / \mathrm{d} T\right) \mathrm{d} T,
$$

where $T_{0}$ and $T_{\infty}$ stand for the onset temperature and stop temperature of crystallizing, respectively. $H_{\mathrm{c}}$ is the enthalpy corresponding to freezing temperature and $X_{\mathrm{t}}$ the relative crystallization rate.

Figure 4 shows the relation between the crystallization rate $\left(X_{\mathrm{t}}\right)$ of $\mathrm{Ni}-\mathrm{W}-\mathrm{P}$ ternary alloy coating melt and the crystallization temperature $(T)$. In figure 4, during the nonisothermal crystal processing with different cooling rates, the relative crystallization rate of the alloy coating melt, $X_{\mathrm{t}}$, has a series of reverse $S$-shape curves with the temperatures.

The relationship between the crystal temperature and the crystallization time, $t$, is as following:

$$
t=\left|T_{0}-T\right| / \phi,
$$

where $T_{0}$ is the onset temperature of crystal, $\phi$ the cooling rate. Therefore, the connection between the relative crystallization rate, $X_{\mathrm{t}}$, and the crystallization time, $t$, at different cooling rates can be depicted as another form shown in figure 5. It can be seen from figure 5 that the faster the cooling rate, the shorter the crystallization time needed. This result was in good agreement with those reported in the study by Yang et al. ${ }^{26}$ That is, the crystallization rate firstly increases and then reduces in the later transformation stage. 


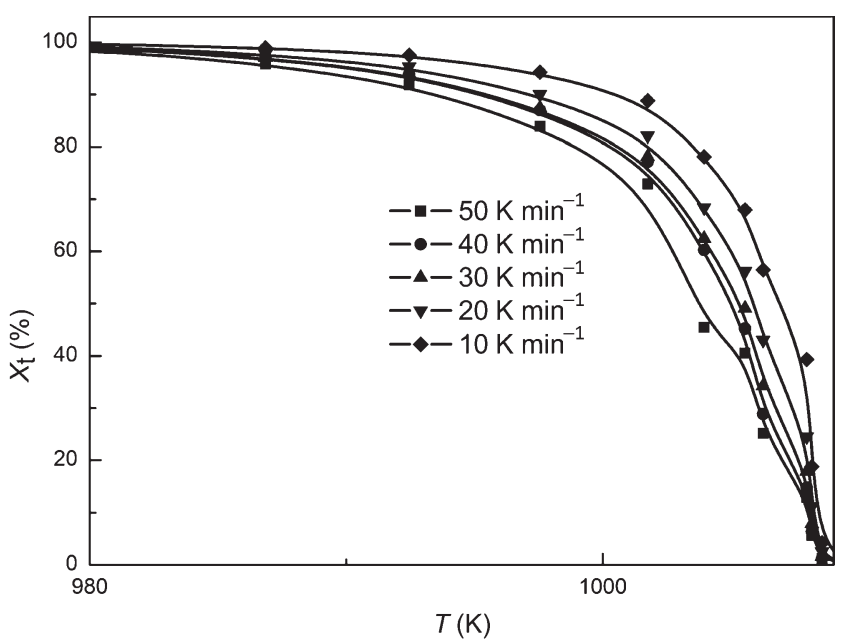

Figure 4. Relation between the crystallization rate $\left(X_{\mathrm{t}}\right)$ and the crystallization temperature $(T)$ of the Ni-W-P ternary alloy coating melt. The non-isothermal crystal processing with different cooling rates, the relative crystallization rate of Ni-W-P alloy coating melt has a series of reverse $S$-shape curves with the temperatures.

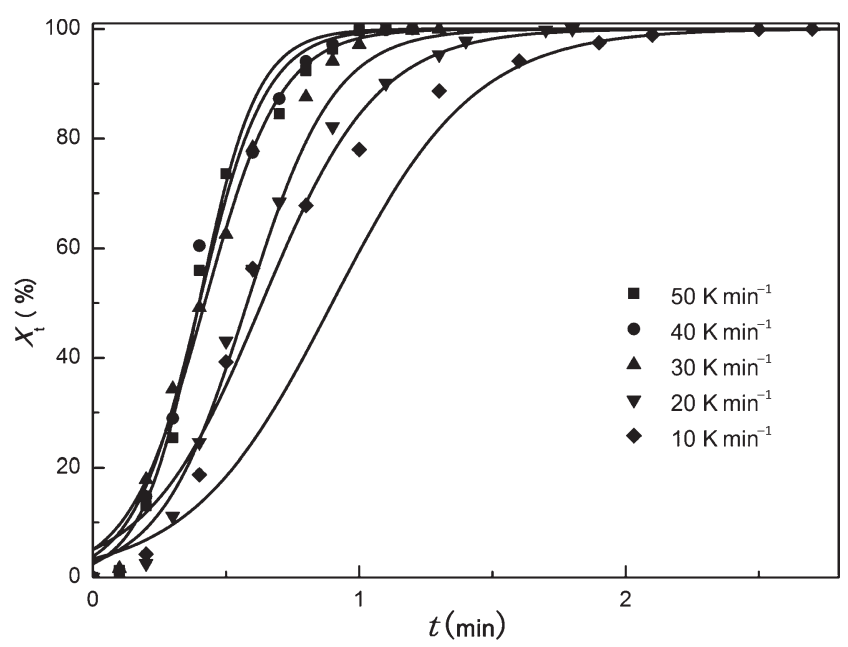

Figure 5. The connection between the relative crystallization rate $\left(X_{\mathrm{t}}\right)$ and the time $(t)$ at different cooling rates of the Ni-W-P ternary alloy. The faster the cooling rate, the shorter the crystallization time needed.

The isothermal crystallization process is the main stage during non-isothermal crystallization; it can be expressed as following Avrami equations:

$$
\begin{aligned}
& 1-X_{\mathrm{t}}=\exp \left[-Z_{\mathrm{t}} t^{n}\right], \\
& \log \left\{-\ln \left[1-X_{\mathrm{t}}\right]\right\}=n \log t+\log Z_{\mathrm{t}},
\end{aligned}
$$

where $n$ is the progressions of the reaction correlated to the nucleus type and nucleus growth process parameters; $Z_{\mathrm{t}}$ the frequency factor, correlated to the nucleus formation and nucleus growth parameters during the isothermal process.

The frequency factor, $Z_{\mathrm{t}}$, deduced from formula (3), should be revised properly for the characteristics of the non-isothermal crystallization. Supposing the cooling rate,

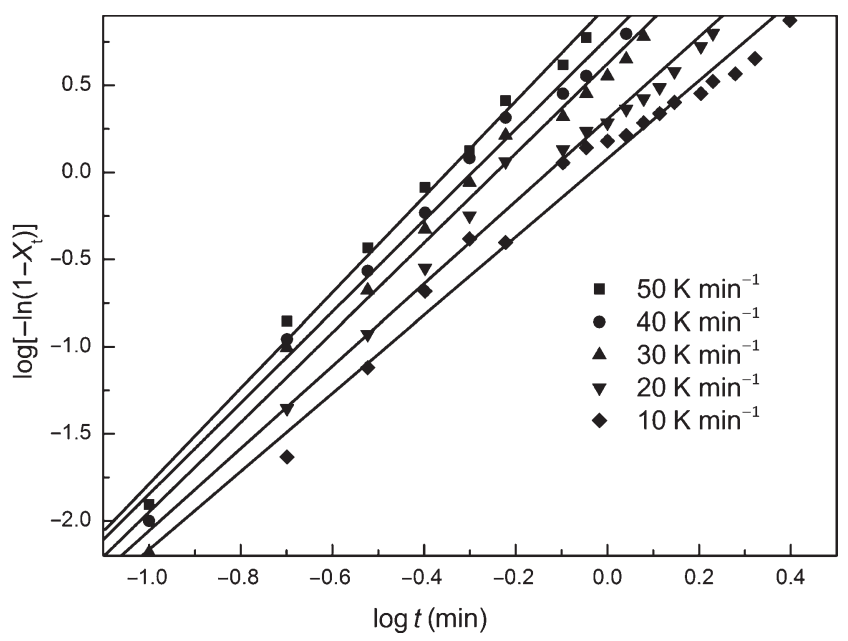

Figure 6. Plots of $\log \left[-\ln \left(1-X_{\mathrm{t}}\right)\right]$ vs. $\log t$ of the Ni-W-P ternary alloy with different cooling rates. The nucleus formation mechanism and growth geometry shape of Ni-W-P alloy coating melts resemble.

$\phi$, is a constant, the revised non-isothermal crystal kinetics frequency factor, $Z_{\mathrm{c}}$, can be expressed as:

$$
\log Z_{\mathrm{c}}=\frac{\log Z_{\mathrm{t}}}{\phi}
$$

There exists a bee-line in each curve for a long crystallization time. Also a linear relationship emerged from the beginning stage to the relative higher stage of the crystallization. This indicates that the non-isothermal crystallization of Ni-W-P alloy coating melt can be described by Avrami equation properly. The increasing of cooling rate will lead to short the finishing crystallization time.

Figure 6 shows the relationship between $\log \left[-\ln \left(1-X_{\mathrm{t}}\right)\right]$ and $\log t$ of the Ni-W-P alloy with different cooling rates. The bee-lines in figure 6 almost paralleled to each other, which indicates that the nucleus formation mechanism and growth geometry shape of Ni-W-P alloy coating melts resemble.

\section{Conclusions}

In order to obtain a deep undercooling in low cooling rates and keep the melt of deep undercooling in liquid for a longer time without solidification, containerless method of flux processing was used to restrain the heterogeneous nucleation and the maximum undercooling of the Ni-20 wt $\% \mathrm{~W}-12$ wt $\%$ P alloy coating melt with $359 \mathrm{~K}$ has been confirmed by DSC curves. which was higher than Ni-P binary alloy with $310 \mathrm{~K}$.

The crystallization was mainly influenced by the cooling rate of the Ni-W-P alloy coating melt. The higher the cooling rate, the shorter the crystallizing time needed for the complete crystallization. When cooling rate is fixed, the change of undercooling depends on the melt processing temperature, and the undercooling will increase rapidly at the first stage. 
The possible explanation to obtain high undercooling may be that an increase of cooling rate will lead to short the finishing crystallization time. Also, an increase of the thermal treatment temperature will remelt and passivate the inclusion in the melt, will be helpful to reduce the heterogeneous nucleation and thus will decrease the possibility of the heredity of atom cluster, which will contribute to the formation of high undercooling.

\section{Acknowledgement}

We would like to thank the financial support from the State Key Laboratory of Metastable Materials Science and Technology Foundation.

\section{References}

1. Pu J, Feng W J, Xiao J Z, Gan Z H, Yi H Y and Cui K 2003 J. Cryst. Growth 256139

2. Balaraju J N, Jahan S M, Jain A and Rajam K S 2007 J. Alloys Compd. 436319

3. Liu H, Guo R X and Liu Z 2012 Trans. Nonferr. Met. Soc. 22 3012

4. Yao H, Zhu G L and Du M 2012 Appl. Mech. Mater. 117-119 1338

5. Yu J K, Jing T F, Yang J and Li Q 2009 J. Mater. Process. Technol. 20914

6. Balaraju J N, Kalavati, Manikandanath N T and William Gris V K 2012 Surf. Coat. Technol. 2062682

7. Panagopoulos C N, Papachristos V D and Christoffersen L W 2000a Thin Solid Films 366155

8. Panagopoulos C N, Papachristos V D, Wahlstrom U, Leisner P and Christoffersen L W 2000b Scr. Mater. 43677

9. Hamid Z A 2003 Surf. Interface Anal. 35496

10. Tien S K, Duh J G and Chen Y I 2004 Surf. Coat. Technol. 177178532
11. Balaraju J N and Rajam K S 2005 Surf. Coat. Technol. 195154

12. Balaraju J N, Jahan S M and Rajam K S 2006 Surf. Coat. Technol. 201507

13. Hu Y J, Wang T X, Meng J L and Rao Q Y 2006 Surf. Coat. Technol. 201988

14. Hamdy A S, Shoeib M A, Hady H and Abdel Salam O F 2007 Surf. Coat. Technol. 202162

15. Chen X M, Li G Y and Lian J S 2008 Trans. Nonferr. Met. Soc. 18 s323

16. Palaniappa M and Seshadri S K 2008 Wear 265735

17. Szczygieł B, Turkiewicz A and Serafińczuk J 2008 Surf. Coat. Technol. 2021904

18. Afroukhteh S, Dehghanian C and Emamy M 2012 Prog. Nat. Sci. 22318

19. Liu L, Wei X X, Huang Q S, Li J F, Cheng X H and Zhou Y H 2012 J. Cryst. Growth 35820

20. Wilde G, Sebright J L and Perepezko J H 2006 Acta Mater. 54 4759

21. Gao Y L, Zhuravlev E, Zou C D, Yang B, Zhai Q J and Schick C 2009 Thermochim. Acta 4821

22. Li Q, Zhu Y Y, Liu R P, Li G, Ma M Z, Yu J K, He J L, Tian Y J and Wang W K 2004 Appl. Phys. Lett. 85558

23. Liu N, Liu F, Yang G C, Chen Y Z, Yang C L and Zhou Y H 2009 J. Alloys Compd. 4611

24. Chen Y Z, Liu F, Yang G C and Zhou Y H 2011 Intermetallics 19221

25. Panofen C and Herlach D M 2007 Mater. Sci. Eng. A 449-451 699

26. Yang W, Liu F, Yang G C, Xu Z F, Wang J H and Wang Z T 2012 Thermochim. Acta $\mathbf{5 2 7} 47$

27. Lin H K, Chen H Y and Lan C W 2014 J. Cryst. Growth 38544

28. Chen Y Z, Yang G C, Liu F, Liu N, Xie H, Chen D, Yang C L, Su Y P and Zhou Y H 2006 Mater. Lett. 601888

29. Yang C L, Liu F, Yang G C and Zhou Y H 2009 J. Cryst. Growth 311404

30. Guan W B, Gao Y L, Zhai Q J and Xu K D 2005 Mater. Lett. 591701 